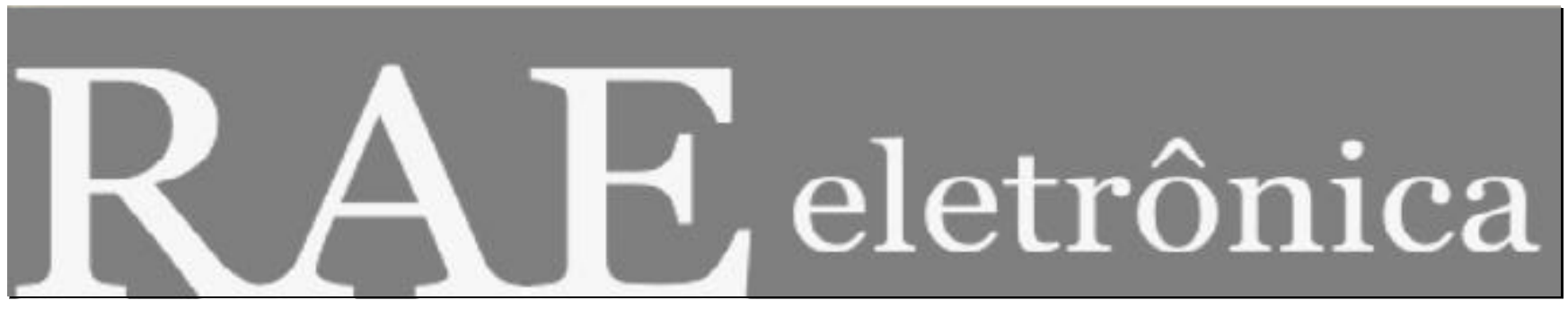

FÓRUM - NOVOS MODELOS ORGANIZACIONAIS: PARADOXOS E CONTRADIÇÕES ENTRE O DISCURSO E A PRÁTICA

\title{
NOVAS FORMAS ORGANIZACIONAIS E OS DESAFIOS PARA OS EXPATRIADOS
}

Por:

Ivana Dolejal Homem, Universidade de Passo Fundo

Eloise Helena Livramento Dellagnelo, UFSC

RAE-eletrônica, v. 5, n. 1, Art. 8, jan./jun. 2006

http://www.rae.com.br/eletronica/index.cfm?FuseAction=Artigo \&ID=3355\&Secao=Fórum $\&$ Volume= $5 \&$ Numero $=1 \&$ Ano $=2006$

CCopyright, 2006, RAE-eletrônica. Todos os direitos, inclusive de tradução, são reservados. É permitido citar parte de artigos sem autorização prévia desde que seja identificada a fonte. A reprodução total de artigos é proibida. Os artigos só devem ser usados para uso pessoal e nãocomercial. Em caso de dúvidas, consulte a redação: raeredacao@fgvsp.br.

A RAE-eletrônica é a revista on-line da FGV-EAESP, totalmente aberta e criada com o objetivo de agilizar a veiculação de trabalhos inéditos. Lançada em janeiro de 2002, com perfil acadêmico, é dedicada a professores, pesquisadores e estudantes. Para mais informações consulte o site www.rae.com.br/eletronica.

RAE-eletrônica ISSN 1676-5648

(C2006 Fundação Getulio Vargas - Escola de Administração de Empresas de São Paulo.

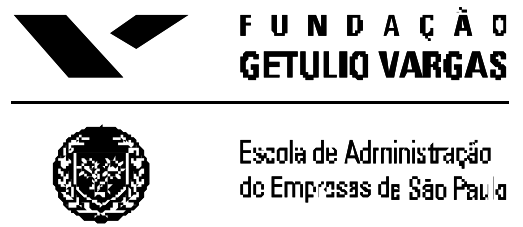




\title{
RESUMO
}

As mudanças decorrentes da abertura dos mercados e rápidas transformações tecnológicas trouxeram para as organizações a necessidade de repensar e reformular seus modos de trabalhar por meio de novos arranjos organizacionais. Esses arranjos têm acarretado modificações de ordem tecnológica, estrutural e cultural nas organizações e conduzem a uma série de impactos no trabalho do indivíduo. O objetivo deste artigo teórico é estabelecer relações entre as novas formas organizacionais e as mudanças que vêm ocorrendo no mundo do trabalho, em especial a questão dos executivos "sem fronteiras". Nesse ambiente de mudanças percebem-se evidências relevantes para a caracterização das novas formas e também contrastes e contradições oriundos das relações entre os expatriados e as organizações.

\section{PALAVRAS-CHAVE}

Novas formas organizacionais, gestão de pessoas, multiculturalismo, expatriação.

\begin{abstract}
Changes caused by the opening of markets and fast technological transformations created for the organizations the necessity to rethink and to reformulate their ways to work through new organizational arrangements. These arrangements have caused modifications of technological, structural and cultural order leading to a series of impacts upon the work of the individual. The objective of this article is to establish relations between the new organizational forms and the changes taking place in the world of work, in special the question of the executives "without borders". In this changing environment evidences appear for the characterization of the new forms and also contrasting and deriving contradictions of the relations between expatriates and organizations are perceived.
\end{abstract}

\section{KEYWORDS}

New organizational forms, people management, multiculturalism, expatriation. 


\section{INTRODUÇÃOO}

A partir das últimas décadas têm surgido muitas pesquisas e discussões a respeito dos estudos e teorias que compreendem as práticas organizacionais e as mudanças no mundo do trabalho. Nesse sentido, vários termos surgem com o intuito de "rejuvenescer" a teoria organizacional e caracterizar essas transformações. Dentre eles, destacam-se flexibilidade, redesenho organizacional, novos paradigmas, pós-modernismo, modelo pós-industrial, modelo pós-burocrático e, de forma mais específica, downsinzing, equipes de trabalho, empowerment, organizações de aprendizagem e redes organizacionais (Dellagnelo e Silva, 2000).

De acordo com os estudos de Dellagnelo e Silva (2000), as novas formas organizacionais vêm sendo discutidas, basicamente, sobre dois aspectos: como representação de uma lógica de ação diferente da instrumental, que é típica do modelo modernista de organização, e como simples aperfeiçoamento da abordagem contingencial da administração. Desse modo, a burocracia tradicional e os modelos hierárquicos de organização do trabalho têm sido altamente criticados por serem inflexíveis para acompanhar as exigências de velocidade e qualidade requeridas pelo mercado atual.

Victor e Stephens (1994) defendem a idéia de que as alterações na natureza das formas organizacionais são ocasionadas por mudanças de uma magnitude que não tem sido vista desde a Revolução Industrial e a conseqüente emergência da burocracia. Para muitos estudiosos do pósmodernismo, essas mudanças são alavancadas por modismos gerenciais, que acabam sendo utilizados como práticas de "uso comum" e nas "supostas" adequações ao novo contexto mundial. Com isso, essas práticas acabam, muitas vezes, implementadas de maneira superficial ou não condizente com a realidade da empresa.

Para Dellagnelo (2000), as principais perspectivas que justificam a procura de novas formas organizacionais podem ser divididas em três grandes esferas: desenvolvimento tecnológico, aumento da competitividade no mercado global e estabelecimento de um mercado mais exigente. Os estudos da autora, respaldados em Galbraith e Lawler III (1995), definem que essas esferas devem ser permeadas por elementos-chave como: estratégia, estrutura, processos, recompensas e pessoas, haja vista a necessidade de criação de competências e capacidades que possibilitem mudanças constantes e sobrevivência em ambientes altamente competitivos.

Nesse cenário em que estão imersas as organizações, são necessárias novas estratégias de perpetuação e gestão. Motta e Vasconcelos (2002, p. 302) salientam que "para desenvolver-se e 
sobreviver, o grupo organizacional tem dois grandes problemas a solucionar: adaptar-se ao ambiente e manter sua coerência interna". Adaptar-se ao ambiente significa estar constantemente evoluindo e adotando estratégias que os torne m competitivos. Manter a coerência interna requer, principalmente, ter indivíduos executando com eficácia e eficiência suas funções e subsistemas organizacionais, trabalhando com interdependência e harmonia. Ou seja, exigir dos trabalhadores a interiorização de novos atributos e valores profissionais, como o individualismo e a competição.

No plano global, para terem sucesso, as empresas precisam ser: (a) competitivas através do mundo; (b) eficientes; (c) localmente responsáveis; (c) flexíve is e adaptáveis dentro de um curto espaço de tempo; (d) capazes de transferir conhecimento e aprendizagem por meio de suas unidades geograficamente dispersas (Schuler, Budhwar e Florkowiski, 2002). Logo, a análise desse discurso remete a uma organização que deve possuir sujeitos capazes de dar conta do trabalho diversificado, decorrente do processo de expansão e sobrevivência no mercado mundial.

Sendo assim, o que se vem presenciando é o desenvolvimento de organizações hiperflexíveis, adaptativas e inovadoras (Dellagnelo, 2000). Segundo Huber e Glick (1993), os desenhos de organizações, que são flexíveis, que se adaptam e criam mudanças, que mais eficazmente usam seus talentos e tecnologia, são talvez as mais significantes variáveis das novas formas. Essas são oriundas de modificações não apenas na estrutura, tecnologia e cultura organizacional, mas principalmente na natureza do trabalho.

Para Dellagnelo (2000), as mudanças na natureza do trabalho tornam o trabalho mais abstrato do que físico, mais desenhado para equipes do que para indivíduos, mais fluido e difuso, sem respeitar fronteiras, e menos confinado a unidades e organizações. Entretanto, essas transformações no mundo do trabalho afetam não apenas as organizações com sua exigência de mobilidade, flexibilidade e eficácia, mas, principalmente, os indivíduos. As empresas têm exigido dos trabalhadores que sejam competitivos, desenvolvam as competências necessárias à execução de suas tarefas, e se comprometam com o projeto da empresa, dedicando-se à realização de seus objetivos e metas. Em contrapartida, o indivíduo deve estar atento ao mercado e às outras organizações, mantendo sua rede de contatos, caso fique desempregado. Ou seja, a organização deixa claro que a relação empregatícia é transitória, pois sua estadia e permanência dentro daqueles limites fronteiriços também o são (Vasconcelos e Crubellate, 2004).

O paradoxo organizacional evidenciado anteriormente retrata uma economia hipercompetitiva refugiada nos processos de fusões, aquisições e alianças estratégicas como base de um novo mercado, caracterizado por ambientes organizacionais extremamente complexos, diversificados e permeados de 
FÓRUM - NOVOS MODELOS ORGANIZACIONAIS: PARADOXOS E CONTRADIÇÕES ENTRE O DISCURSO E A PRÁTICA NOVAS FORMAS ORGANIZACIONAIS E OS DESAFIOS PARA OS EXPATRIADOS Ivana Dolejal Homem - Eloise Helena Livramento Dellagnelo

relações multiculturais. ${ }^{1}$ Uma variedade de situações de trabalho, como curtas viagens de negócios para outros países, longos tempos de missão no estrangeiro e no próprio dia-a-dia de trabalho dentro da organização, são oriund as dessas interações cross-cultural ${ }^{2}$ (Black e Mendenhall, 1990).

O surgimento de ambientes de trabalho mais heterogêneos exige do trabalhador de empresas com unidades geograficamente dispersas o desenvolvimento de novas habilidades, como a de se responsabilizar individualmente pela superação das dificuldades impostas pelo trabalho e as mudanças em seu contexto. Gosling e Mintzberg (2003) evidenciam claramente as contradições existentes nas relações de trabalho dos profissionais "sem fronteiras", quando salientam que, "hoje, o executivo é instado a ser global e local; a colaborar e competir; a mudar sem parar e a manter a ordem; a cumprir metas financeiras e cuidar bem do pessoal” (Gosling e Mintzberg, 2003, p. 41).

Para Luz (1999), o grande desafio do executivo internacional é vencer a perspectiva do paroquialismo, pois ser paroquial é não reconhecer outros mundos diferentes de viver e trabalhar; é a tendência de ver o mundo pela ótica da própria cultura e não considerar que essas diferenças têm conseqüências sérias. É dentro dessa perspectiva que as organizações globais têm aumentado a procura de executivos cosmopolitas, que tenham experiências de pessoas e coisas de diferentes partes do mundo. Ser cosmopolita pode ser considerado como sinônimo de ter maior facilidade para lidar com situações que reque iram experiências cross-cultural, e, de forma mais ampla, é a capacidade de integrar imperativos aparentemente contraditórios.

Os paradoxos que caracterizam o contexto das novas formas e, em consequiência, das relações de trabalho revelam o surgimento de um grupo de trabalhadores dispersos pelo mundo "sem fronteiras" por meio das designações internacionais, ou seja, executivos expatriados. Caligiuri (2000) define como expatriados os executivos que são enviados por uma empresa multinacional para viver e trabalhar em um país estrangeiro por um período de no mínimo dois anos.

Os expatriados representam um novo desenho organizacional, comum nas organizações modernas, onde o contato intercultural revela a necessidade de adaptação a novos costumes, hábitos, crenças e valores, em ambientes culturalmente diversificados. Porém, ao mesmo tempo, que remete à adaptação define situações onde as diferenças entre os indivíduos de culturas diferentes podem provocar prazer ou sofrimento, desafio ou confusão (Joly, 1993).

Buscando estabelecer relações entre as novas formas organizacionais e as transformações no mundo do trabalho, em especial a questão dos executivos "sem fronteiras", o presente artigo se propõe a caracterizar as novas formas organizacionais e a desvendar os paradoxos existentes nas relações entre expatriados e organizações. 
Para tanto, o artigo será composto de três partes. A primeira parte discute as questões relativas às novas formas organizacionais e o contexto do mundo do trabalho, bem como suas implicações para os expatriados. As evidências e contradições das novas formas em ambientes multiculturais são tratadas na segunda parte, onde se procura contrastar o novo cenário organizacional, permeado de exigências e limitações para a vida do expatriado. Por fim, a última parte traz algumas considerações sobre o assunto desenvolvido.

\section{AS NOVAS FORMAS ORGANIZACIONAIS SOB A ÓTICA DOS PROFISSIONAIS EXPATRIADOS}

Muitos são os aspectos que devem ser observados na definição das novas formas organizacionais. Entretanto, um dos aspectos mais citados pela literatura acadêmica diz respeito à necessidade de as organizações serem flexíveis para acompanhar as mudanças do mercado altamente competitivo do qual fazem parte. (Daft e Lewin, 1993; Huber e Glick, 1993; Victor e Stephens, 1994; Volberda, 1996, 1998; Dellagnelo e Silva, 2000; Sennett, 2002).

Clegg (1990) afirma que as novas formas surgiram a partir da década de 1980, questionando o modelo burocrático como maneira mais eficiente para a organização do trabalho. Uma outra explicação, oferecida por Volberda (1998), é que esses novos modelos estão dentro de um continuum, onde o afastamento do modelo burocrático e a tendência a um maior grau de flexibilização em sua estrutura, sua cultura e tecnologia colaboram para o desenho de organizações modernas. Esses três aspectos vêm sendo reorganizados pelas organizações para produzirem ambientes de trabalho mais flexíveis e prontos para rápidas mudanças. Com isso, a abordagem adotada para a análise dos novos modelos organizacionais privilegiará o estudo dos três atributos: tecnologia, estrutura e cultura, para fins de desenvolvimento deste artigo.

A utilização de tecnologias modernas tem ajudado as organizações a conseguirem melhor qualificação e mudanças em seu ambiente de trabalho. Aproveitar o potencial oferecido pelas tecnologias é comum nas organizações globais. Volberda (1996) define a tecnologia como o hardware (máquinas e equipamentos) e o software (conhecimento) usados na transformação de entradas em saídas e suas configurações.

A tecnologia tem o poder de permitir às pessoas trabalharem no tempo e nos lugares de suas próprias escolhas. Ela tem o potencial enorme de transcender os limites geográfico, cultural e temporal e, assim, aumentar a colaboração entre as organizações e seus membros, fomentando o contato 
FÓRUM - NOVOS MODELOS ORGANIZACIONAIS: PARADOXOS E CONTRADIÇÕES ENTRE O DISCURSO E A PRÁTICA NOVAS FORMAS ORGANIZACIONAIS E OS DESAFIOS PARA OS EXPATRIADOS Ivana Dolejal Homem - Eloise Helena Livramento Dellagnelo

intercultural. Contudo, a tecnologia incorporada por meio de máquina e equipamentos pode ser percebida como intrusa e controladora, no momento em que fornece às organizações a capacidade de monitorar o desempenho do empregado mais de perto e altera as relações de liderança e controle entre os grupos de trabalho (Cartwright, 2003).

Para a autora supracitada, o conhecimento pode ser mais extensamente compartilhado e disseminado com a tecnologia. Entretanto, uma comunicação entre indivíduos por meio dos meios eletrônicos reduz os aspectos sociais da comunicação associados ao trabalho em conjunto. Nesse sentido, é também mais difícil a percepção das diferenças culturais entre os membros de uma organização espalhados geograficamente se o contato for somente por meio eletrônico. Telefones, emails e outras "próteses" tecnológicas criam um filtro de contato entre as pessoas que pode mascarar as relações sociais e dificultar a compreensão dos aspectos culturais, principalmente quando existe posteriormente um processo de expatriação entre os profissionais de uma organização.

A tecnologia também é responsável pelo formato da estrutura organizacional. Organizações mais flexíveis tendem a possuir tecnologias de hardware e software adequadas a necessidades imprevisíveis e de rápidas mudanças do ambiente, bem como realizam mudanças estruturais para se adequarem aos desafios da competitividade.

De acordo com Volberda (1996), as estruturas organizacionais compreendem não somente a distribuição de responsabilidades e autoridade entre as pessoas da organização (forma básica), mas também o planejamento, os sistemas de controle, a coordenação e execução dos processos de trabalho. O desenho estrutural da organização pode variar de mecanicista a orgânico (Hatch, 1997; Wagner III e Hollenbeck, 2000).

Para Hatch (1997), formas de organização mecanicistas são caracterizadas por altos níveis de complexidade, formalização e centralização. O trabalho é divido e subdividido em tarefas altamente especializadas. Ao trabalhador é concedida autonomia limitada na execução de suas tarefas; regras e procedimentos são claramente definidos; e há limitada participação nas tomadas de decisões, as quais tendem a ser conduzidas por um alto nível de gerenciamento.

Em contraste, para Wagner III e Hollenbeck (2000) as estruturas orgânicas são como organismos vivos, no sentido de que são flexíveis e capazes de se adaptar a situações externas variáveis. Assim, em vez de apresentarem uma autoridade hierárquica, as organizações orgânicas têm os seguintes aspectos: estrutura de controle em rede descentralizada, em hierarquias achatadas; ajustes e redefinições contínuos das tarefas; contexto de comunicação que envolve informação e orientação (Hall, 1984; Wagner III e Hollenbeck, 2000). 
Estruturas orgânicas estão sendo introduzidas em larga escala nas organizações modernas. Aos profissionais em atribuições internacionais, por exemplo, é concedida ampla autonomia para a realização de suas tarefas, e os objetivos e metas das expatriações são claros e bem definidos. Eles devem ser capazes de se adaptar a situações de mudanças e são responsáveis por disseminar o conhecimento entre subsidiárias. De acordo com a nomenclatura de Tung (1981), os expatriados podem ser de quatro tipos: (1) executivo oficial principal, cuja responsabilidade é gerenciar e dirigir a operação inteira; (2) reprodutor de estruturas ou cabeça funcional, cujo trabalho é estabelecer departamentos funcionais, ou seja, levar conhecimento gerencial e técnico para membros das subsidiárias; (3) atacante de problemas, cuja função é analisar e resolver um problema operacional específico que os membros da filial estrangeira não estão conseguindo resolver; ou simplesmente, (4) um elemento ou membro comum da organização.

Assumir alguma dessas posições, requer do expatriado um conjunto de características que o qualifiquem para a execução de seu trabalho, como as seguintes: maior autonomia individual, capacidade de constituir equipes de trabalho, adaptação e integração em ambientes multiculturais, desenvolvimento de função cruzada (aprendizado contínuo e treinamento cruzado), entre outras. Essas características resultam de novas configurações globais, denominada novas formas organizacionais.

Não somente mudanças estruturais, mas também mudanças culturais podem ser necessárias num ambiente de mudanças tecnológicas, principalmente para aumentar a competitividade de uma empresa e sua sobrevivência no mercado atual. As mudanças estruturais, de políticas de emprego e novos métodos de trabalho, resultam em mudanças de normas sobre o comportamento apropriado, que freqüentemente desafiam ou estão em conflito com a cultura organizacional existente (Cartwright, 2003). A cultura organizacional pode ser entendida como

[...] um conjunto de pressupostos básicos que um grupo inventou, descobriu ou desenvolveu ao aprender como lidar com os problemas de adaptação externa e integração interna e que funcionou bem o suficiente para ser considerado válido e ensinado a novos membros como a forma correta de perceber, pensar e sentir, em relação a esses problemas. (SCHEIN, 1996, p. 432).

Segundo Grouard e Meston (2001), a cultura abrange a maneira como os funcionários se socializam, as atitudes com o trabalho, os relacionamentos interpessoais, bem como a importância dedicada às diferentes funções da empresa. A posição dos clientes e como eles são tratados, o modo de vestir e se portar nas dependências da empresa, a forma como são feitas as negociações entre países, podem também ser vistas como aspectos culturais. Desse modo, para os autores, a cultura tem uma 
FÓRUM - NOVOS MODELOS ORGANIZACIONAIS: PARADOXOS E CONTRADIÇÕES ENTRE O DISCURSO E A PRÁTICA NOVAS FORMAS ORGANIZACIONAIS E OS DESAFIOS PARA OS EXPATRIADOS

Ivana Dolejal Homem - Eloise Helena Livramento Dellagnelo

influência muito forte na maneira como uma empresa conduz suas atividades, define sua estrutura e escolhe sua tecnologia.

A cultura organizacional, para Volberda (1996), pode variar de conservadora a inovadora, dependendo do grau de normas correntes e sistemas de valores utilizados como ferramentas estratégicas. A cultura conservadora consiste em uma forte e homogênea identidade e tem uma estreita influência. Os líderes aplicam um estilo de liderança diretivo. Há grande disseminação de regras resultantes de uma forte disciplina dominante, processo de socialização e de uma baixa tolerância e ambigüidade. Mais do que isso, uma cultura conservadora tem uma orientação externa fechada, que é principalmente de curto prazo e reativa, ou seja, restringe severamente o potencial para a flexibilidade. Em contraste, uma cultura inovadora tem uma fraca e heterogênea identidade, e uma grande influência. Os líderes aplicam um estilo de liderança delegatória e são inclinados à improvisação. Há poucas regras disseminadas como consequiência de uma baixa disciplina dominante (livre troca de conhecimento e informação entre os vários departamentos), fraco processo de socialização e alto nível de tolerância e ambigüidade. A orientação externa é muito aberta e o longo prazo, orientado (Volberda, 1996). Esta última denominação é comum em organizações desterritorializadas, em que o fraco processo de socialização decorrente de uma cultura inovadora é marcado pelo paradoxo adaptação e integração em um curto espaço de tempo para os profissionais que trabalham atravessando fronteiras.

A análise do discurso feito até este ponto sugere que organizações com uma cultura organizacional mais fortemente compartilhada e uniforme tenderiam a ser menos eficazes para procederem a rápidas mudanças e se adaptarem a ambientes complexos, turbulentos e competitivos. Organizações com culturas inovadoras, formadas por grupos de diversas áreas e múltiplas culturas (como os expatriados), tendem a ser mais flexíveis. Segundo Freitas (1991, p. 72), "num ambiente complexo e com mudanças freqüentes, como o atual, as organizações se tornam cada vez mais complexas, diversificadas e diferenciadas para sobreviver". Desse modo, trabalhar com múltiplas culturas pode ajudar na eficácia organizacional e no desenvolvimento de organizações mais flexíveis.

Dentro dessa perspectiva, Tung (1998) afirma que é preciso que as organizações desenvolvam uma nova geração de gerentes, os cosmopolitas, que são ricos em três recursos intangíveis: conceitos, competências e conexões. Para a autora, uma maneira de desenvolver gerentes cosmopolitas é enviá-los para designações internacionais onde possam assumir uma ampla escala de obrigações e responsabilidades, desenvolvendo e aprimorando esses três recursos. Os cosmopolitas são, por definição, membros da classe mundial. Eles transportam conceitos de um lugar para outro e integram atividades disseminadas no mundo inteiro. São também o retrato de um novo desenho organizacional, 
FÓRUM - NOVOS MODELOS ORGANIZACIONAIS: PARADOXOS E CONTRADIÇÕES ENTRE O DISCURSO E A PRÁTICA NOVAS FORMAS ORGANIZACIONAIS E OS DESAFIOS PARA OS EXPATRIADOS Ivana Dolejal Homem - Eloise Helena Livramento Dellagnelo

marcado pela condição paradoxal de permanência versus transitoriedade e apego versus desapego familiar, emocional e territorial.

Huber e Glick (1993) observam que as novas práticas são ricas em oportunidades para mudanças positivas nas organizações e muitos gestores estão tirando vantagens dessas oportunidades, criando novas e eficazes formas organizacionais. O sucesso e a sobrevivência das organizações globais dependem, em muito, dos gestores, principalmente os que são expatriados. Eles têm papel fundamental na disseminação do conhecimento para as subsidiárias pelos seguintes motivos: (1) identificam e abrem novos mercados; (2) facilitam uma fusão ou aquisição; (3) instala m novas tecnologias e sistemas; (4) aumentam a participação de mercado ou impedem que os competidores o façam; (5) desenvolvem visão de longo prazo de negócios em países estrangeiros; (6) transferem conhecimento para profissionais locais; (7) aprendem e geram idéias inovadoras; e (8) geram novos conhecimentos para a organização ou adquirem habilidades que ajudarão no desenvolvimento de lideranças globais (Black e Gregersen, 1999; Halcrow, 1999).

No entanto, Victor e Stephens (1994) apresentam uma visão mais crítica sobre as novas formas e destacam que o redesenho organizacional necessariamente acarreta não só ganhos, mas também perdas para a organização e para o trabalhador. Segundo os autores, a flexibilidade organizacional representada pelo downsizing, inserção de novas tecnologias, contratos temporários de trabalho, entre outros, acarreta a diminuição dos postos de trabalho. Segue-se a falta de comprometimento por parte das organizações, aumento da pressão por trabalhadores mais criativos, inovadores e que se adaptem a ambientes de trabalhos mais turbulentos, culturalmente diversificados e sujeitos a mudanças.

A nova organização que aprende, exige também a automotivação do empregado, fazendo com que aprenda e tenha que buscar constantemente aperfeiçoamento para não cair na obsolescência e perder seu emprego (Victor e Stephens, 1994). Para esses articulistas, pouco se tem criticado as novas formas organizacionais, que trazem diversos aspectos negativos no relacionamento do trabalhador com a organização. Se de um lado a organização exige trabalhadores extremamente comprometidos, por outro lado essa organização oferece pouca ou nenhuma garantia em detrimento da incessante busca de flexibilidade. Eis que surgem verdadeiros paradoxos organizacionais decorrentes de novas formas de organização e disseminação do trabalho para além das fronteiras geográficas.

\section{EVIDÊNCIAS E CONTRADIÇÕES DAS NOVAS FORMAS ORGANIZACIONAIS EM AMBIENTES MULTICULTURAIS}


FÓRUM - NOVOS MODELOS ORGANIZACIONAIS: PARADOXOS E CONTRADIÇÕES ENTRE O DISCURSO E A PRÁTICA NOVAS FORMAS ORGANIZACIONAIS E OS DESAFIOS PARA OS EXPATRIADOS

Ivana Dolejal Homem - Eloise Helena Livramento Dellagnelo

A diversificação dos ne gócios e a exploração de novos mercados internacionais trouxeram a necessidade de repensar os processos de trabalho, a preocupação com o desenho dos novos arranjos organizacionais e com o modo de gerenciar os recursos humanos. Adicionalmente, esse contexto de mudanças em que estão inseridas as companhias multinacionais tem alterado as relações de trabalho e contribuído para o surgimento de paradoxos organizacionais.

Um dos desafios que enfrentam as organizações enquanto globalizam suas operações é a adaptação de suas práticas de recursos humanos para o novo conjunto de culturas no qual a organização está operando e a criação de formas de operação que sejam ao mesmo tempo confortáveis para a organização e apropriadas para aquelas culturas e indivíduos. Esses desafios dos mercados globais são concretizados por firmas de todo o mundo, e o número e variedade de culturas representam mudanças também em sua força de trabalho (Schuler, 2000). Outro fato importante é que essas forças de trabalho são mescladas por múltiplas culturas. Seja pela necessidade de recrutar pessoas com habilidades específicas e/ou técnicas para gerenciar ou conduzir negócios em diferentes partes do mundo (expatriação), ou pelo fato de não existirem mais barreiras geográficas entre as nações devido à intensificação das fusões, aquisições e alianças estratégicas. Essas alterações na força de trabalho são responsáveis por diversas mudanças de situações no ambiente de trabalho e na vida dos trabalhadores.

Sennett (2002) observa que a maneira de organizar o tempo é o fator que mais afeta a vida emocional das pessoas dentro e fora do local de trabalho. E, assim, argumenta que hoje não se dá mais espaço para o longo prazo. Troca-se de emprego diversas vezes durante uma vida profissional, mudamse tarefas, os locais de trabalho e funcionários da noite para o dia. Tudo is so norteado pela lógica mercadológica na qual o rápido retorno financeiro é gerado pela rápida mudança institucional. Assim como mudam de pessoas, também as empresas mudam de local, num enorme vai-e-vem entre países, que exige de alguns profissionais o desapego da sua pátria-mãe e a interiorização de novas crenças, valores e cultura em um curto espaço de tempo.

As mudanças de país decorrentes das exigências do trabalho e a falta de espaço para o longo prazo podem levar à perda de laços afetivos profundos. Essa perda torna o indivíduo mais receptivo a processos de desterritorialização, ou seja, ele não pertence mais a um lugar específico, não está mais preso a raízes familiares, muito menos de vizinhança (Freitas, 2000). Sua rede de relacionamentos sociais sofre também grandes alterações. A rede de relações sociais inclui pessoas disponíveis e relacionamentos que são percebidos pelo indivíduo por prover recursos para tratar com situações tensas (Black, 1990). Aos profissionais que são expatriados, por exemplo, torna-se necessária uma reconstrução dos laços afetivos quando aportam no país estrangeiro. 
FÓRUM - NOVOS MODELOS ORGANIZACIONAIS: PARADOXOS E CONTRADIÇÕES ENTRE O DISCURSO E A PRÁTICA NOVAS FORMAS ORGANIZACIONAIS E OS DESAFIOS PARA OS EXPATRIADOS Ivana Dolejal Homem - Eloise Helena Livramento Dellagnelo

Desse modo, a relação com o trabalho ou com o lugar do trabalho pode se tornar a principal referência do expatriado, assumindo voluntariamente o papel de fornecedora de identidades tanto social quanto individual, contaminando o espaço privado e buscando estabelecer com o indivíduo uma relação de referência total (Freitas, 2000). Para Black, Mendenhall e Oddou (1991), quando um expatriado sai de uma condição familiar e entra em uma não familiar, velhas rotinas são interrompidas, criando incertezas psicológicas. Essa interrupção invoca um desejo por reduzir a incerteza inerente à nova situação, especialmente em consideração a novos comportamentos que podem ser requeridos ou esperados. Para reduzir essa incerteza, o expatriado pode apegar-se a situações que lhe tragam segurança, e um dos poucos elos de ligação que tem com seu país de origem é o espaço físico do local de trabalho.

Sennett (2002) afirma que a instabilidade e a incerteza sempre estiveram presentes na história humana. A grande diferença é que nos dias atuais aparecem sem nenhum desastre iminente. A tensão está ao nosso lado diariamente, tornando-se o que o autor chama de ansiedade trivial. Es se cenário também desperta nos trabalhadores o que ele chamou de um sentimento de deriva, que seria a falta de propósito em relação ao presente e de perspectivas futuras. Ou seja, a nova realidade econômico-social, que traz atributos excitantes de trabalho, como agilidade, flexibilidade e mudança, não propicia a realização de permanência ambicionada por esses trabalhadores, e consequientemente surge a construção discursiva da transitoriedade no posto de trabalho como condição normal de existência das empresas (Vasconcelos e Crubellate, 2004). Assim se corroem no indivíduo as qualidades que criam os laços entre os seres humanos e lhes conferem uma identidade sustentável.

No caso específico do presente estudo, o paradoxo permanência versus transitoriedade revela, nos indivíduos que se deslocam com suas famílias para países "estranhos", ao serem expatriados, certa angústia e ansiedade, pois a desterritorialização é uma experiência que envolve o indivíduo e sua família de maneira intensa, que mobiliza fortemente as suas energias emocionais, favorecendo a criação de expectativas legítimas. Coloca o indivíduo frente a frente com muitas situações para as quais o expatriado e sua família não estavam preparados nem mesmo na sua imaginação (Freitas, 2000).

Sennett (2002) adverte ainda que uma grande diferença dos dias atuais é o fato de o risco tornarse algo a ser enfrentado diariamente pelas massas, e assim, para se estar ativo no mercado de trabalho é necessário gostar de viver na incerteza. Correr riscos, deixando de lado experiências partilhadas e realizações e talentos pessoais, é viver no limite. Para o autor, um dos perigos de se permanecer no contínuo estado de vulnerabilidade reside no fato de que a exposição ao risco pode corroer o caráter do trabalhador; à medida que as coisas mudam diariamente, estamos sempre começando do zero, e instala- 
FÓRUM - NOVOS MODELOS ORGANIZACIONAIS: PARADOXOS E CONTRADIC̃̃ES ENTRE O DISCURSO E A PRÁTICA NOVAS FORMAS ORGANIZACIONAIS E OS DESAFIOS PARA OS EXPATRIADOS Ivana Dolejal Homem - Eloise Helena Livramento Dellagnelo

se uma situação de vale-tudo. Ou seja, o sentimento de permanência e de continuidade que o indivíduo experimenta em suas relações sociais e perde em situações de mudança de trabalho para outros países desconstrói a identidade do trabalhador.

A capacidade de assumir riscos é uma das exigências das empresas na contratação de pessoal, e vem afetando um grupo de trabalhadores com mais desejo de tarefas, crescimento pessoal (pessoas com uma mistura de promessas e experiências, na precoce meia fase de sua carreira) e rápida ascensão profissional. São pessoas que provavelmente têm família jovem e uma escala de boas opções alternativas de carreira, ou seja, as que possuem o perfil adequado para as designações internacionais (Franke e Nicholson, 2002).

A pressa das companhias em obter sucesso nos negócios internacionais tem conduzido ao risco esses executivos expatriados. Impulsionadas pela concorrência, as empresas expõem os indivíduos a longos períodos de trabalho no exterior. Uma experiência que, por vezes, não se faria necessária (Franke e Nicholson, 2002). Joly (1993) reconhece ainda que viver no exterior, num ambiente culturalmente diferente do de origem, é uma experiência que mergulha o indivíduo em confusão. Para a articulista, a experiência intercultural passa a ser, antes de qualquer coisa, uma experiência de desestruturação-reestruturação da personalidade, que faz dos ambientes de trabalho verdadeiros espaços de contradições e riscos para os trabalhadores expatriados.

Outra situação de risco a que as empresas por vezes expõem os expatriados é o medo de retorno prematuro ou falha na atribuição. Para evitar um fracasso na missão, normalmente selecionam profissionais superqualificados para assumirem posições de nível inferior à exercida no país de origem. Essa questão impacta de maneira negativa a vida do trabalhador e pode ser caracterizada com uma experiência decepcionante, uma vez que esses profissionais possuem elevado grau de competência e experiência para suas missões internacionais. Segundo Bolino e Feldman (2000), quando os expatriados são subempregados ${ }^{3}$ durante sua missão no exterior, fatores como saúde mental, atitudes no trabalho e desempenho auto-reconhecido são prejudicados. Além disso, muitos deles têm seus contratos de trabalho modificados ou cancelados no país de origem para se adequarem às exigências de leis estrangeiras, ou mesmo pela simples falta de comprometimento por parte da organização, que não garante ao expatriado o retorno à mesma função executada antes da transferência de país.

$\mathrm{Na}$ atualidade, é possível observar que as contradições existentes nos ambientes de trabalho multiculturais decorrem muitas vezes da crescente busca, da parte das empresas, de profissionais superqualificados. Trabalhadores cosmopolitas, flexíveis, criativos, multifuncionais, polivalentes, reativos e outros tantos termos usados como sinônimos e que representam a grande capacidade de 
FÓRUM - NOVOS MODELOS ORGANIZACIONAIS: PARADOXOS E CONTRADIÇÕES ENTRE O DISCURSO E A PRÁTICA NOVAS FORMAS ORGANIZACIONAIS E OS DESAFIOS PARA OS EXPATRIADOS Ivana Dolejal Homem - Eloise Helena Livramento Dellagnelo

mudar constantemente. Os expatriados estão entre a classe de profissionais em que mais cresce a procura de "supertrabalhadores". Eles devem portar, entre outras tantas características, sensibilidade interpessoal, interesses culturais e sociais, habilidades relacionais e técnicas, busca de realização, trabalho como prioridade de vida, autonomia, extroversão, fluência de línguas, disponibilidade para treinamento e preparação, registro baixo de doença, poucos laços de família Franke e Nicholson, 2002). A organização deve ser o centro da vida do trabalhador, e atingir os objetivos da expatriação, o seu maior desafio.

Dellagnelo (2000) observa que um novo contrato psicológico passa a ser necessário nas relações de trabalho oriundas dos novos desenhos organizacionais. Para a autora, esse contrato reflete a compreensão do indivíduo em termos de vínculo empregatício com a organização, bem como as crenças sobre aquilo que é esperado dos empregados em retorno à organização. Fish (1999) salienta a necessidade de a empresa deixar claro quais são as expectativas e desempenhos esperados do expatriado na execução do trabalho. Is so inclui a definição do tipo de trabalho a ser desenvolvido, o local da atribuição, as compensações, benefícios e suportes oferecidos pela organização com o intuito de minimizar o choque cultural e encurtar o processo de adaptação.

Dentro da ótica da flexibilidade, as carreiras hierárquicas passam a ser revistas, e surgem novas perspectivas para a rotação de cargos baseadas em alocações dos empregados em diferentes projetos, conforme afirma Dellagnelo (2000). Esses projetos são implementados em várias partes do mundo e requerem do trabalhador a disponibilidade para mudanças de residência por meio das chamadas missões internacionais de trabalho. Essas exigências contribuem para uma cultura de desapego ao passado e impelem as pessoas a uma situação de assumir riscos. Para Sennett (2002), o imediatismo das organizações flexíveis leva a uma desvalorização da experiência acumulada do indivíduo.

A busca incessante pela flexibilidade mobiliza não apenas a organização. Ser flexível torna-se condição de sobrevivência para o indivíduo tanto no trabalho quanto na vida. "O ser flexível tornou-se o sonho dourado de todas as empresas, e conseguir ser flexível, a necessidade desesperada, o pesadelo dos executivos atuais, por ser condição de sobrevivência” (Freitas, 2000, p. 12).

Black e Mendenhall (1990) afirmam ainda que, para os expatriados obterem sucesso numa designação internacional, são necessárias características relacionadas à interação cross-cultural, entre elas: habilidades relacionadas à preservação do eu (saúde mental, bem-estar psicológico, redução do estresse, sentimentos de auto-confiança); habilidades relacionadas ao encorajamento de relacionamentos com os nativos (sociabilidade, habilidade de comunicação, confiança mútua) e habilidades cognitivas (permitem a correta percepção do ambiente hospedeiro e seus sistemas sociais). 
Essas características são relacionadas a fatores psicossociais, e não são fáceis de serem "controladas" ou modificadas a qualquer momento pelos sujeitos. Entretanto, parece que falta essa percepção às organizações, já que exigem dos profissionais, durante uma expatriação, características específicas de conduta, personalidade e ação decorrentes de situações de trabalho variadas.

Percebe-se que as constantes mudanças no ambiente de trabalho e no contexto mundial têm levado os indivíduos a criarem mecanismos de melhoria pessoal que acompanhem todas as evoluções da organização. Entretanto, essas evoluções exigem muito mais do que proatividade, criatividade, dinamismo, flexibilidade e características pessoais únicas. Elas levam os indivíduos a conviverem com antagonismos nunca antes vistos, pois o tipo de ser que as organizações pretendem formar e possuir em seus quadros é um retrato das contradições que abrigam em seu próprio interior.

As empresas exigem do indivíduo a convivência pacífica com os imperativos contraditórios que para Freitas (2000) são expressos, quando dizem ao indivíduo para ser combativo, agressivo, individualista, mas, ao mesmo tempo, para colaborar e integrar-se na equipe; pedem que ele seja inovador, criativo, ousado, mas que obedeça à tradição e não provoque rupturas; elas querem que ele tenha iniciativa, mas seja obediente; ele deve ser orgulhoso de estar na equipe, mas deve sempre provar que merece o lugar do outro.

As expatriações englobam as exigências do mercado de trabalho atual e tendem a gerar nos executivos todo um conjunto de experiências que acompanham e afetam suas expectativas de evolução pessoal, profissional, de representações sociais e de avaliação de suas próprias competências. Mais do que isso, Mendenhall e Oddou (1985) salientam ainda que há também riscos invisíveis devido à falha de um gerente nas missões internacionais: a perda da auto-satisfação e da auto-confiança nas habilidades gerenciais do expatriado, e o custo de ter de volta um empregado insatisfeito e desmotivado para o trabalho atual.

Entretanto, entender o processo do multiculturalismo em que as organizações multinacionais estão sendo paulatinamente inseridas, quer seja pela necessidade de fazerem negócios internacionais, quer seja pelo fato de possuírem pessoas de diferentes culturas, é uma exigência a que todos os trabalhadores estão sujeitos no seu ambiente de trabalho. Esse novo desenho organizacional está cada dia mais comum dentro das organizações modernas e merece um amplo debate no campo de estudos organizaciona is. 


\section{CONSIDERAÇÕES FINAIS}

A internacionalização das empresas, o surgimento de novas tecnologias em constante mutação e a necessidade de as empresas estarem constantemente assimilando e interagindo com essas mudanças criam ambientes de trabalho mais complexos, diversificados e difíceis de administrar. Essas mudanças surgem como um novo desenho organizacional, frente à crescente competitividade do mundo dos negócios, e implicam a busca incessante de flexibilidade.

Além disso, a natureza do trabalho passa a ser mais dinâmica, criativa e sujeita a mudanças, exigindo, assim, habilidades multifuncionais do empregado, a auto-organização e a constituição de novas equipes de trabalho. A ruptura de alguns padrões formais, como o aumento do grau de autonomia dos empregados e a diminuição dos níveis hierárquicos, é um dos fatores relacionados aos redesenhos organizacionais que vêm sendo implementados em várias empresas para melhorar seus graus de eficiência.

Para Sennett (2002), a sociedade de hoje busca meios de destruir os males da rotina, com a criação de organizações mais flexíveis, onde um comportamento flexível gera liberdade pessoal. Para o autor, o comportamento humano flexível deve ter uma força maleável para adaptar-se a circunstâncias variáveis, mas não ser quebrado por elas. Entretanto, para ele, a economia política vigente trai o desejo pessoal de liberdade. A repulsa à rotina burocrática e a busca da flexibilidade produzem novas estruturas de poder e controle, em vez de criar condições que libertem o indivíduo.

A própria questão dos ambientes multiculturais revela o surgimento de trabalhadores desterritorializados, muito menos apegados aos locais de trabalho, à família e à pátria, com elevada capacidade de assumir riscos, "treinados" e impelidos a se ajustarem rapidamente ao contexto. Esses profissionais globais e locais fazem parte dos novos arranjos das organizações modernas, permeados de contradições e exigências. São representados também pelos profissionais expatriados e correspondem a um grupo de trabalhadores em crescente ascensão m mundo atual, onde a vida sobre pressão, risco e instabilidade é parte do cotidiano e não desperta nenhum tipo de surpresa.

Entretanto, não há como fugir desse novo contexto mundial. As novas formas organizacionais surgem como resposta a um novo paradigma que vem tomando conta das estruturas econômicas e sociais. O paradigma da competitividade selvagem, da escassez de empregos e recursos, da tecnologia mutante e das novas relações de trabalho. 
Diante desse contexto, as relações existentes entre a organização e o indivíduo têm apresentado muitos paradoxos, tendo em vista a grande necessidade de adaptação a ambientes diversos e em constante mudança. Entretanto, as contradições desses novos arranjos organizacionais são mais percebidas pelos indivíduos dentro dos seus locais de trabalho, pois a empresa, na busca de melhores negócios, menores custos e aumento de mercado, tem criado novas exigências em suas relações de trabalho. Essas novas exigências são muitas vezes uma via de mão única, onde somente o indivíduo deve cumprir as "regras", sem nenhuma garantia de comprometimento por parte da empresa.

O que se observa é que a falta de regras e limites para a concorrência mundial tem conduzido pessoas e organizações a um grande ciclo de mudanças. Não se pode afirmar se esse novo ciclo levará a uma ruptura com o modelo dominante de capitalismo ou o transformará. O presente artigo é uma contribuição para alertar e fomentar pesquisas sobre a expansão dos novos modelos organizacionais em detrimento das relações de trabalho vigentes. Consequientemente, carrega muitos paradoxos, que à primeira vista tornam-se difíceis de vislumbrar, mas que levam os trabalhadores do mundo atual a um repensar contínuo sobre a vida pessoal e profissional. Contudo, a análise do discurso no qual se deteve o artigo demonstra que existem limitações à aplicação do estudo, tendo em vista que ele possui cunho teórico e que os trabalhos nessa área ainda são incipientes, necessitando de pesquisas empíricas para sua comprovação.

\section{NOTAS}

1 Multicultural: composto por várias culturas; refere-se também a pessoas que têm diferenças de costumes e crenças (Cambridge Dictionaries Online. Disponível em <http://dictionary.cambridge.org/define.asp?key=52460\&dict=CALD >. Acessado em 20 abr. 2004).

2 "Contatos entre duas ou mais pessoas de diferentes experiências culturais" Black e Mendenhall, 1990, p. 113).

3 Os indivíduos são considerados "subempregados" quando estão trabalhando em trabalho inferior, menor ou de uma qualidade mais baixa em relação a algum padrão definido (Bolino e Feldman, 2000).

\section{REFERÊNCIAS BIBLIOGRÁFICAS}

BARROS, B. T.; RODRIGUES, S. B. Compreendendo a dimensão cultural. Encontro das culturas organizacionais. In: BARROS, B. T.; RODRIGUES, S. B. Fusões, aquisições \& parcerias. São Paulo: Atlas, 2001. p. 103-123. 
BLACK, J. S. The relationship of personal characteristics with the adjustment of Japanese expatriate managers. Management International Review, v. 30, n. 2, p. 119-134, 1990.

BLACK, J. S.; GREGERSEN, H. B. The right way to manage expats. Harvard Business Review, v. 77, n. 2, p. 52-60, 1999.

BLACK, J. S.; MENDENHALL, M. E. Cross-cultural training effectiveness: a review and a theoretical framework for future research. Academy of Management Review, v. 15, n. 1, p. 113-136, 1990.

BLACK, J. S.; MENDENHALL, M. E.; ODDOU, G. R. Toward a comprehensive model of international adjustment: an integration of multiple theoretical perspectives. Academy of Management Review, v. 16, n. 2, p. 291-317, 1991.

BOLINO, M. C.; FELDMAN, D. C. The antecedents and consequences of underemployment among expatriates. Journal of Organizational Behavior, v. 21, n. 8, p. 889, 2000.

CALIGIURI, P. M. Selecting expatriates for personality characteristics: a moderating effect of personality on the relationship between host national contact and cross-cultural adjustment. Management International Review, v. 20, p. 61-80, 2000.

CARTWRIGHT, S. New forms of work organization: issues and challenges. Leadership \& Organization Development Journal, v. 24, n. 3, p. 121-122, 2003.

CLEGG, S. Modern Organizations: Organization Studies in the Postmodern World. London: Sage Publications, 1990.

DAFT, R. L.; LEWIN, A. Y. Where are the theories for the "new" organizational forms? An editorial essay. Organization Science, v. 4, n. 4, p. 1-7, nov. 1993.

DELLAGNELO, E. H. L. Novas formas organizacionais: ruptura com o modelo burocrático? Florianópolis, 2000. 179 f. (Tese de Doutorado em Engenharia de Produção). Universidade Federal de Santa Catarina. 
FÓRUM - NOVOS MODELOS ORGANIZACIONAIS: PARADOXOS E CONTRADIÇÕES ENTRE O DISCURSO E A PRÁTICA NOVAS FORMAS ORGANIZACIONAIS E OS DESAFIOS PARA OS EXPATRIADOS Ivana Dolejal Homem - Eloise Helena Livramento Dellagnelo

DELlAGNELO, E. H. L.; SILVA, C. L. M. Novas formas organizacionais: onde se encontram as evidências empíricas de ruptura com o modelo burocrático de organizações? Organizações \& Sociedade, v. 7, n. 19, p. 19-33, 2000.

FRANKE, J.; NICHOLSON, N. Who shall we send? Cultural and other influences on the rating of selections criteria for expatriate assignments. International Journal of Cross Cultural Management, London: Sage Publications, v. 2, n. 1, p. 21-36, 2002.

FREITAS, M. E. Multiculturalismo e expatriação nas organizações: vida do executivo expatriado, a festa vestida de riso ou de choro. In: DAVEL, E.; VERGARA, S. C. (Orgs.). Gestão com pessoas e subjetividade. São Paulo: Atlas, 2001. p. 289-302.

FREITAS, M. E. Contexto social e imaginário organizacional moderno. Revista de Administração de Empresas. São Paulo, v. 40, n. 2, p. 6-15, 2000.

FREITAS, M. E. Como vivem os executivos expatriados e suas famílias? Relatório de Pesquisa, n. 7, EAESP/FGV/NPP - Núcleo de Pesquisas e Publicações, 2000, p. 1-117. Disponível em <http://www.fgvsp.br/adm/arquivos_npp/P00078_1.pdf>. Acessado em 10 nov. 2004.

FREITAS, M. E. Cultura Organizacional: formação, tipologias e impacto. São Paulo: Makron, McGraw-Hill, 1991. p. 19-26.

GOSLING, J.; MINTZBERG, H. As cinco mentes de um executivo. Harvard Business Review, novembro, 2003.

GROUARD, B.; MESTON, F. Empresa e mudança. Os domínios da mudança. In: GROUARD, B.; MESTON, F. Empresa em movimento. São Paulo: Negócio Editora, 2001. p. 1-36.

HALCROW, A. Expats: the squandered resource. Workforce, v. 78, n. 4, p. 42-52, 1999.

HALL, R. H. Organizações: estrutura e processos. Rio de Janeiro: Prentice Hall do Brasil, 1984.

HATCH, M. J. Organization theory: modern symbolic and postmodern perspectives. Oxford: Oxford University Press, 1997. 
FÓRUM - NOVOS MODELOS ORGANIZACIONAIS: PARADOXOS E CONTRADIÇÕES ENTRE O DISCURSO E A PRÁTICA NOVAS FORMAS ORGANIZACIONAIS E OS DESAFIOS PARA OS EXPATRIADOS

Ivana Dolejal Homem - Eloise Helena Livramento Dellagnelo

HUBER, G. P.; GLICK, W. H. What was learned about organization change and redesign. In: HUBER,

G. P.; GLICK, W. H. Organizational Change and Redesign: Ideas and Insights for Improving Performance. New York: Oxford, 1993. p. 383-391.

JOLY, A. Alteridade: ser executivo no exterior. In: CHANLAT, J. F. Coord.). O indivíduo na organização: dimensões esquecidas. São Paulo: Atlas, v. 1, 1993.

LUZ, T. R. Desafios da gerência internacional e novas competências. In: RODRIGUES, S. B. (Org.). Competitividade, alianças estratégicas e gerência internacional. São Paulo: Atlas, 1999. p. 233-252.

MENDENHALL, M. E.; ODDOU, G. R. The dimensions of expatriate acculturation: a review. Academy of Management Review, v. 10, n. 1, p. 39-47, 1985.

MOTTA, F. C. P.; VASCONCELOS, I. F. G. Teoria geral da administração. São Paulo: Pioneira Thomson Learning, 2002. p. 299-329.

SCHEIN, E. H. Organizational Culture and Leadership. San Francisco: Jossey-Bass, 1996.

SCHULER, R. S. The internationalization of human resource management. Journal of International Management. Elsevier Science, Inc., v. 6, p. 239-260, 2000.

SCHULER, R. S.; BUDHWAR, P. S; FLORKOWISKI, G. W. International human resource management: review and critique. International Journal of Management Reviews. Oxford: Blackwell Publisher, v. 4, n. 1, p. 41-70, 2002.

SENNETT, R. A corrosão do caráter. Rio de Janeiro: Record, 2002.

TUNG, R. L. Selecting and training of personnel for overseas assignments. Columbia Journal of World Business, v. 16, n. 2, p. 68-78, 1981.

TUNG, R. L. American expatriates abroad: from neophytes to cosmopolitans. Journal of World Business, v. 33, p. 125-144, 1998.

VASCONCELOS, I. F. G.; CRUBELLATE, J. M. Transitoriedade e permanência nas relações de trabalho: discursos paradoxais para a (des)construção social da identidade. In.: VASCONCELOS, F. 
FÓRUM - NOVOS MODELOS ORGANIZACIONAIS: PARADOXOS E CONTRADIÇÕES ENTRE O DISCURSO E A PRÁTICA NOVAS FORMAS ORGANIZACIONAIS E OS DESAFIOS PARA OS EXPATRIADOS

Ivana Dolejal Homem - Eloise Helena Livramento Dellagnelo

C.; VASCONCELOS, I. F. G. (Orgs.). Paradoxos organizacionais: uma visão transformacional. São Paulo: Pioneira Thomson Learning, 2004. p. 255-285.

VICTOR, B.; STEPHENS, C. The dark side of the new organizational forms: an editorial essay. Organization Science, v. 5, n. 4, p. 479-482, 1994.

VOLBERDA, H. W. Toward the flexible form: how to remain vital in hypercompetitive environments. Organization Science, v. 7, n. 4, p. 359-374, 1996.

VOLBERDA, H. W. Building the flexible firm: how to remain competitive. New York: Oxford University Press, 1998.

WAGNER III, J. A.; HOLLENBECK, J. R. Comportamento organizacional: criando vantagem competitiva. São Paulo: Saraiva, 2000.

Artigo enviado em 30.04.2004. Aprovado em 14.09.2005.

\section{Ivana Dolejal Homem}

Professora da Universidade de Passo Fundo. Mestre em Administração pela Universidade Federal de Santa Catarina.

Interesse de pesquisa nas áreas de gestão internacional de pessoas, sentido do trabalho, flexibilização do trabalho, novas formas de organização do trabalho.

E-mail: ivanadh@yahoo.com

Endereço: Universidade de Passo Fundo, Campus I, km 171, BR 285, Bairro São José, Caixa Postal 611, Passo Fundo - RS, 99001-970.

\section{Eloise Helena Livramento Dellagnelo}

Professora da Universidade Federal de Santa Catarina. Doutora em Engenharia da Produção pela Universidade Federal de Santa Catarina.

Interesse de pesquisa nas áreas de comportamento e organização.

E-mail: eloise@cse.ufsc.br

Endereço: Universidade Federal de Santa Catarina, Centro Socioeconômico, Curso de Pós-Graduação em Administração, Campus Universitário, Trindade, Cx. Postal 476, Florianópolis - SC, 88040-900. 